\title{
Analysis on Current Development of Internet Service Mode Based on Innovative Product Design
}

\author{
Xiaodong Yuan \\ Zhengzhou University of Aeronautics \\ Zhengzhou, China 450046
}

\begin{abstract}
The fast development of information technology and economic globalization makes the service mode that provides internet users with product design and development become possible. Under current international environment, there are few researches on internet service mode aiming at product design. Under current situation, it is very necessary to analyze and research internet service mode for users that centers on innovative product design and development situation of integrated system of product design at the present stage in theory of service design.
\end{abstract}

Keywords - internet; product design; service design

\section{INTRODUCTION}

From agrarian age to industrial age to information era, technology strength continuously promotes human beings to create a new world. The internet is using the force that can change everything to bring about profound transform that influences all levels of human being in global range. At this time, human beings stand in the front of the arrival of new age. [1] In the 15 th year of 21 st century of human being, with the change of world manufacturing from centralized control to decentralized enhanced control and the proposal of Germany "industry 4.0" concept, the target of manufacturing industry development of human being at the present stage has centered on the theme about how to set up a highly flexible production mode with personalized and digital product and customer service.

\section{Challenges Faced at the Present Stage}

At present, aiming at the field of service design, the design circles research the influence of service design on industrial products and two aspects of product design method and quality assurance under the premise that meets maximum demands of users. The research on how to deeply integrate two respects, create new user service mode and let it serve innovative product design under influence of this tendency is faced with the following challenges:

1.Integrate the advantages of principle and method of multidisciplinary comprehensive optimization design of industrial design, comprehensively enrich theory and field of quality assurance of product design, verify product quality assurance method of industrial design, define indicator system for quality evaluation of product design, build related mathematical model among goal, content and method of product quality assurance system based on the requirements of multidisciplinary comprehensive optimization design of industrial design, divide the quality assurance method of products of multidisciplinary comprehensive optimization design of industrial design into the following aspects: Check and evaluate through a variety of theoretical methods, many product test and customer use as well as comparing innovative contents. [2] Make the four methods depend on each other, comprehensively apply, build new user service mode, completely and objectively evaluate the success or failure of product design, and provide reference of inspection, supervision and decision-making for manufacturers in enterprises of our country.

2. Innovative product service design system is not perfect temporarily. Product service design is an entirety with open cycle established by two sides of supply and demand. It contains two concepts of product design and service design at the same time. It is a novel field in the development of current design science. [3] Under the current situation that industrial design enters and hosts the discipline of great design, after innovative product service design system contacts users on the basis of product and is used; apply feedback information and requirements of users to creation, definition and planning of later product service mode under systematic guidance of theories and methods of great design. This kind of remedial service design form not only results in the waste of various resources, even makes it worse after remediation. This is because most of the previous design methods of product service do not completely start from practical application situation of users, but determine the way and content of product design through depending on designers' use of creative design methods. Although it opens up development space of innovative thinking of product design, it does not keep the people-oriented original intention of design. [4]

3. The accumulation of knowledge about service mode that influences product design is insufficient. In current era of experience economy, products and service are sold out in the staged process of experience. In this process, users cannot directly enjoy service without buying products, but enjoy service after the existence of products. Under this kind of sales pattern, although manufacturers design, develop and analyze products, because clear relationship of hierarchical mapping is lacked between quality assurance of product design and service mode, it results in the fact that the decode procedure of theory of product designers and decode procedure of service design of product users form an extensive open-loop system. 
[5] Therefore, under current situation, it requires product manufacturers to consider using what kind of service mode to better establish an experience mode of product in advance and make the manufacturing of product meet the requirements of users.

\section{RESEARCH StATUS AND DEVELOPMENT TREND AT THE PRESENT STAGE}

With the development of modern service industry, science and technology such as service science, service management, service engineering and service computing also grow rapidly. Service continuously intersects and integrates with all walks of life and many fields of science and technology. The concept of service design with industrial design attribute contents produced in intersection of theory and service of industrial design receives more and more attention from experts and scholars in many fields such as product manufacture, service economy management and information service.

\section{A. Development of Thoughts and Theories in Whole Horizon of Ecological Technology and Service of Enterprise Products}

It is well-known that enterprise products will change with time, users, service environment, use-pattern, aesthetic standard of users as well as progress of science and technology. These changes will finally make the products become out of fashion and lack attraction, and then users will eliminate them through selection. Or they avoid being eliminated by users through upgrading and updating of products. In the ecological horizon of enterprise products created by subjective reasons and objective reasons jointly, it is always the primary content of development research of product design theory to think about how to make enterprise escape the negative effects brought by the elimination of products or make the negative effects on enterprises become the smallest. [6] According to these ecological characteristics of products, foreign researchers put forward relation model of new product and service combining Eco-Technology and Eco-Mind from perspectives of relationships between products and manufacturers as well as products and users. This model bases on the development foundation of thoughts and theories in whole horizon of ecological technology of product and service, points out evolution of relationships between products and manufacturers as well as users. It provides basis for researching service mode that centers on products, and provides reference for building system model that centers on product design under internet condition. Meanwhile, it clearly points out the entry point for research that changes primary relationship between things and people, which has dominated human society for thousands of years.

\section{B. Influence of Theory of Product Quality such as QFD, TQC and TQM on Product Design}

In the last century, two Japanese professors, Yoji Akao and Shigeru Mizuno, put forward the research on the direction of product quality management. During the subsequent several decades, on the levels of product quality management and assurance of customer satisfaction, they develop a series of matched management methods of QFD (Quality Function
Deployment), which finally evolve into methods of TQC (Total Quality Control) and TQM (Total Quality Management), which are well-known today. The purpose of these methods is to make product design and manufacturing fully meet the requirements of customers. It emphasizes that enterprises shall listen to "the voice of customers" in the development process of product or service, which lift the curtain on today's service design. The supreme goal of theory of product quality such as QFD, TQC and TQM is that a quality control method shall embody the requirements of customers before products are manufactured, and then ensure customers' degree of satisfaction. The value estimating method of product quality control has the same position. In manufacturing process of products or quality problems are found after the production is finished, it introduces the theory of value engineering and measures the increase and decrease in variable of product design and the value of operation procedure. This method can continuously improve products and processes according to the requirements of customers, in order to reduce costs and improve the quality. It makes today's well-known product design method that centers on users and guarantees the quality of design process. [6]

It is observed that at present, the research on product design mainly focuses on enterprises, market and customers' use value related to product quality under the background of service economy. At the present stage, the key to determine product value is the problem that it is difficult for manufacturers and users to unify the standard of product value. It also points out the direction for this task to find effective design methods.

\section{Research Method of Value Co-creation (VCC) Related to Product and Service Design}

Recently, under the background of product and service design innovation, using the quantity of product value to measure the achievements of product design and service design is popularized. Researches on creation of product value mainly focus on shimosuwa model under perspective of service engineering, UEDA model created by product and service value on system level in creative engineering and SDL model of value creation under service dominant logic put forward by some scholars of industrial design in Japan and some great powers of design in Europe. Here it is worth enumerating in full detail is the research on Value Co-Creation received from the perspective of relationship attributes of products. The existing VCC research mainly focuses on the "interaction" of suppliers, customers and internet as well as creation of value under service dominant logic. This research verifies the quantity of value of products created by them jointly through integrating resources and abilities of all sides, and then compares according to the quantity of value, finally judges the success or failure of product and service design. In the process of VCC, the establishment of relevant roles and relationships and the development of scale of manufacturers' and customers' Value Co-Creation behavior provide basis for VCC to verify service design of business model and become one of the research contents that receive the most attention in the fields of product design and service design in the world at the present stage at one stroke. However, there are scholars 
who make critical analysis on Value Co-Creation created jointly by VCC theory under S-D Logic mode and designing intensive business services.

Although for research on VCC, some people support and praise it and some people oppose and criticize it, we can find that in internet era, the research on user service model that centers on product design can completely create advantages for subsequent research on VCC. Meanwhile, it wins over more powerful theoretical supports for scholars who support the perspective of this research.

\section{APPLICATION PROSPECT OF INTERNET ERA}

At the present stage, in terms of the above analysis, the research on product design and service mode presents complex and multidisciplinary characteristics, mainly distributes in fields such as management, design science, psychology, aesthetics and mechanical engineering, involves research on aspects such as development process and feedback of design from the perspective of product; life cycle assessment and quality assurance method from the perspective of quality; consuming behavior, psychology and emotionalized design from the perspective of users.

With the arrival of internet era, the spread of academic development becomes rapid and global. The research direction of scholars at home and abroad on this subject has surpassed regional limitation. Especially for research on product design of service mode, the update on professional degree of research at home and abroad is almost synchronous. The research on product design of service mode can not only enrich continuous research and development of theoretical techniques and approaches in quality assurance of product design, but also in quality control and assurance of product design, use achievements of application research and practice under plenty of internet service mode to prove actual application value of quality assurance theory of product design in detail and the use of broadening principle and method of multidisciplinary comprehensive optimization design. At the same time, it explores user experience, brand and creation of perceptual value from perspectives such as psychology, social anthropology and aesthetics, and relationships between product design and service mode of these aspects. It raises the past researches that are scattered and lack regularity and uniformity, especially the researches on product design and service mode that start from the perspective of industrial design subordinating the great design, to a new research platform.

\section{CONCLUSION}

Under the current situation, it seems to be more and more important to use the method of multidisciplinary comprehensive optimization design in industrial design, combining knowledge of theory of product quality assurance and research on user service mode that centers on innovative product design. It is found through practical application that in design stage, it can correctly change customers' requirements into definition of product; in manufacturing stage, it can change definition of product that reflects customers' requirements into correct manufacturing process of product and produce through distribution between enterprises, and then completely meet customers' requirements; in the stage of customer use, it can organically connect feedback of usage information of users with manufacturers' development of subsequent products through relevant service such as aftersales service of products and update service of products, and truly realize connecting innovation, technology, business, design and customers. In addition, it establishes better products, experience, use and independent space for users and provides enterprises with new network, service, business value and competitive advantages.

\section{REFERENCES}

[1] CCTV full-length documentary, Internet Era, wrote by the main creative team, Internet Era [M], Beijing United Publishing Co., Ltd, 2015

[2] Zhong Yifang, Chen Baihong, Wang Zhouhong. Principle and Method of Multidisciplinary Comprehensive Optimization Design [M], Huazhong University of Science and Technology Press, 2007

[3] Wang Yue. Service Design Based on Life-style [J], Art and Design (Theory), 2011(05)

[4] Wrote by Scott E. Sampson, translated by Xu Xiaofei, Wang Zhongjie. Service Design Method [M], Tsinghua University Press, 2013

[5] Wrote by Tang Xiaoqing, Wang Meiqing, Duan Guijiang. Theory and Method of Quality Assurance for Product Design [M], Science Press, 2011

[6] Editor-in-chief, Lin Zhihang. Quality Engineering of Product Design and Manufacturing [M], China Machine Press, 2005 